\title{
Lateral torsional buckling analysis of truss-braced timber arches
}

\section{Análisis lateral de pandeo torsional de arcos de madera reforzados}

\section{Kálmán Koris (Corresponding Author)}

Budapest University of Technology and Economics, Department of Structural Engineering

3-9. Muegyetem rkp., Kmf. 85, Budapest, H-1111 (Hungary)

koris.kalman@epito.bme.hu

\section{István Bódi (Main Author)}

Budapest University of Technology and Economics, Department of Structural Engineering

3-9. Muegyetem rkp., Kmf. 85, Budapest, H-1111 (Hungary)

bodi.istvan@epito.bme.hu

Manuscript Code: 1303

Date of Acceptance/Reception: 07.07.2019/22.01.2019

DOI: 10.7764/RDLC.18.2.323

\begin{abstract}
Buckling analysis of arches is an important issue of the design of timber structures containing such structural elements. In the article an analytical and an approximate solution is proposed for lateral torsional buckling analysis of truss-braced timber arches. Application of the proposed methods was introduced by a numerical example. Critical forces calculated by the analytical and approximate methods were also compared to the results of numerical analysis, proving the sufficient accuracy of the different solutions. The effect of different timber truss-bracing solutions on the critical force of the examined timber arch was analysed using the introduced analytical method. The critical force of the examined truss-braced arch was up to two orders of magnitude greater than the critical force without bracing, proving that the consideration of the lateral bracing is important during the design because on the one hand, it ensures the static conformity of the structure, and, on the other hand it leads to more economical structural configuration in terms of lateral torsional buckling. Both analytical and approximate method presented in the article can be used to determine the optimal geometric configuration of the bracing truss in order to maximize the critical force of the laterally braced arch.
\end{abstract}

Keywords: timber arch, stability analysis, lateral torsional buckling, elastic bedding, critical force, timber truss-bracing.

\section{Resumen}

El análisis de pandeo de arcos es un tema importante en el diseño de estructuras de madera que contienen dichos elementos estructurales. En el artículo se propone una solución analítica y una solución aproximada para el análisis de pandeo lateral torsional de arcos de madera de refuerzo. La aplicación de los métodos propuestos se introdujo mediante un ejemplo numérico. Las fuerzas críticas calculadas por los métodos analíticos y aproximados también se compararon con los resultados del análisis numérico, lo que demuestra la precisión suficiente de las diferentes soluciones. El efecto de diferentes soluciones de braguero arriostramiento en la fuerza crítica del arco de madera examinado se analizó utilizando el método analítico introducido. La fuerza crítica del arco de madera reforzado examinado fue de hasta dos órdenes de magnitud mayor que la fuerza crítica sin arriostramiento, lo que demuestra que la consideración del arriostramiento lateral es importante durante el diseño porque, por un lado, garantiza la conformidad estática de la estructura, y, por otro lado, conduce a una configuración estructural más económica en términos de pandeo lateral torsional. Tanto el método analítico como el método aproximado presentados en el artículo se pueden utilizar para determinar la configuración geométrica óptima de la armadura de refuerzo para maximalizar la fuerza crítica del arco reforzado lateralmente.

Due to their favourable strength properties, low self-weight and aesthetic appearance, glulam timber arch girders are often used as main load bearing elements of engineering structures like road bridges, footbridges, hall buildings or sport facilities (Figure 1). These glulam arches may bridge large spans up to $120 \mathrm{~m}$, yet they have slender cross-sections due to economic reasons (Crocetti, 2016). Because of the large span and slender cross section, the stability analysis of these girders is essential during the design process. The upper flanges of these arches are often connected by a timber or steel truss-bracing system. This bracing system increases the buckling strength of the arches, and also fulfils the function of roof carrier, which explains their position at the top flange (Figure 1). Lateral torsional buckling phenomenon of straight timber members such as beams has been thoroughly investigated both theoretically and experimentally (Padmoes, 1990; Eggen, 2000; Bell \& Eggen, 2004; Balaž, 2005; Kuhlmann \& Teichmann, 2006; Xiao, 2014). Design criteria for lateral buckling of such members is also specified in many design codes, such as Eurocode 5 (EN 1995-1-1, 2015) but they are only applicable as long as straight, prismatic timber members with simple loading and boundary conditions are analysed, so that the effective lateral buckling length can be taken from tables. For more complex timber structures such as arches, the design criteria for instability phenomenon are not explicitly presented in the design codes. 


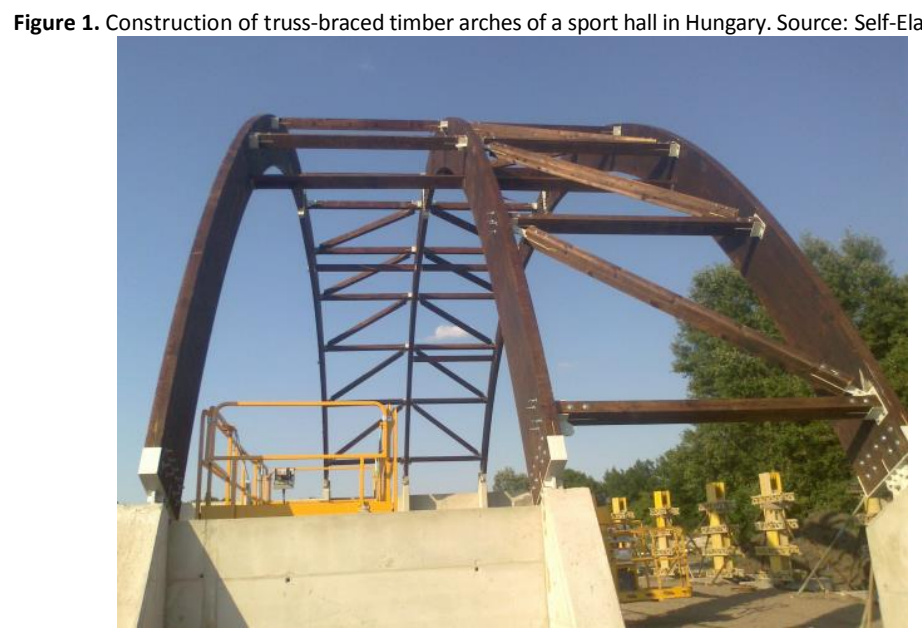

Out-of-plane stability of curved timber beams and arches can primarily be analysed by using the available analytical or numerical methods. For practical design of timber arches the lateral torsional stability is usually verified by numerical modelling, which allows for the consideration of geometric and material nonlinearities, as well as the influence of lateral bracing (e.g. truss-bracing) on the value of critical force (Wollebæk \& Bell, 2004; Rodman et al., 2013; Sherzad \& Imamzada, 2015). The analytical solution for the elastic lateral buckling of standalone curved beams and arches with circular or parabolic shape and different end restraints was also discussed (Timoshenko \& Gere, 1961; Tokarz \&d Sandhu, 1972; Yoo, 1982; Pi \& Bradford, 2004; Lima \& Kang, 2004; Pi et al., 2005; Guo et al., 2014). Although these analytical approaches primarily deal with the stability of metal arches, they can also be applied to timber arches due to the use of the theory of elasticity. An analytical approach for the lateral torsional buckling analysis of arches with continuous lateral support was outlined by Kollár (1982). In this approach the effect of lateral bracing on the stability of the structure was considered by elastic lateral bedding along the whole length of the arch. This approach was applied for the stability analysis of a circular timber arch with hinged supports, laterally braced by a tarpaulin (Kollár \& Bódi, 1984).

Within this article an analytical solution is provided for the calculation of the critical force causing the lateral torsional buckling of truss-braced timber arches. The stiffening effect of the bracing truss is considered by an equivalent, continuous, elastic lateral support for the arch. Based on this solution, an approximate method is also proposed for the calculation of the critical force of truss-braced timber arch structures. The effect of applied truss-brace type and configuration on the critical force of a circular timber arch is also analysed by a numerical example.

Methodology

\section{Buckling analysis of laterally supported arches}

The elastic lateral torsional buckling analysis of arches with continuous lateral support makes it necessary to solve a fourth order, linked differential equation system for the lateral shift $\left(v_{\mathrm{T}}\right)$ and rotation $(\varphi)$ of the shear centre (Kollár \& Bódi, 1984):

$$
\begin{aligned}
& G I_{\mathrm{t}}\left(\varphi^{\prime \prime}+\frac{v_{\mathrm{T}}^{\prime \prime}}{R}\right)-E I_{\omega}\left(\varphi^{\mathrm{IV}}+\frac{v_{\mathrm{T}}^{\mathrm{IV}}}{R}\right)+x_{0} N\left(v_{\mathrm{T}}^{\prime \prime}-x_{0} \varphi^{\prime \prime}\right)-\frac{E I_{\mathrm{x}}}{R}\left(\frac{\varphi}{R}-v_{\mathrm{T}}^{\prime \prime}\right)+ \\
& +N\left(\frac{t-x_{0}}{R}-\frac{i_{\mathrm{x}}^{2}}{R^{2}}\right) \varphi-\left(i_{\mathrm{x}}^{2}-i_{\mathrm{y}}^{2}\right) N \varphi^{\prime \prime}+c t_{\mathrm{c}}\left(v_{\mathrm{T}}-t_{\mathrm{c}} \varphi\right)-g t_{\mathrm{g}}\left(v_{\mathrm{T}}^{\prime \prime}-t_{\mathrm{g}} \varphi^{\prime \prime}\right)=0 \\
& E I_{\times}\left(\frac{\varphi^{\prime \prime}}{R}+v_{\mathrm{T}}^{\mathrm{IV}}\right)+\frac{G I_{\mathrm{t}}}{R}\left(\varphi^{\prime \prime}+\frac{v_{\mathrm{T}}^{\prime \prime}}{R}\right)-\frac{E I_{\omega}}{R}\left(\varphi^{\mathrm{IV}}+\frac{v_{\mathrm{T}}^{\mathrm{IV}}}{R}\right)+ \\
& +N\left(x_{0} \varphi^{\prime \prime}-v_{\mathrm{T}}^{\prime \prime}\right)-c\left(v_{\mathrm{T}}-t_{\mathrm{c}} \varphi\right)-g\left(v_{\mathrm{T}}^{\prime \prime}-t_{\mathrm{g}} \varphi^{\prime \prime}\right)=0
\end{aligned}
$$

where $G l_{\mathrm{t}}$ is the torsional stiffness, $E I_{\omega}$ is the warping stiffness and $E l_{\mathrm{x}}$ is the bending stiffness of the arch cross-section, $R$ is the radius of the arch, $x_{0}$ is the vertical distance between the centre of gravity $(S)$ and the shear centre $(T)$ of the arch crosssection ( $x_{0}=0$ in case of rectangular timber arch cross-sections), $N$ is the axial force causing the lateral torsional buckling of the arch, $t$ is the vertical distance between the shear centre and the point where the external load is acting to the arch (P), $t_{c}$ is the vertical distance between the shear centre and the location of the elastic lateral support of the $\operatorname{arch}(\mathrm{C}), t_{\mathrm{g}}$ is the 
vertical distance between the centre of gravity and the location of the elastic lateral support, $c$ and $g$ are the compressive and shear stiffness of the lateral support for unit arc length, respectively, $i_{x}$ and $i_{y}$ are arch cross-section's radius of gyration values related to the $x$ and $y$ axes. Some of the above mentioned geometrical parameters are illustrated in Figure 2 .

Figure 2. Shape and cross section of a circular glulam arch with the corresponding geometrical parameters. Source: Self-Elaboration.
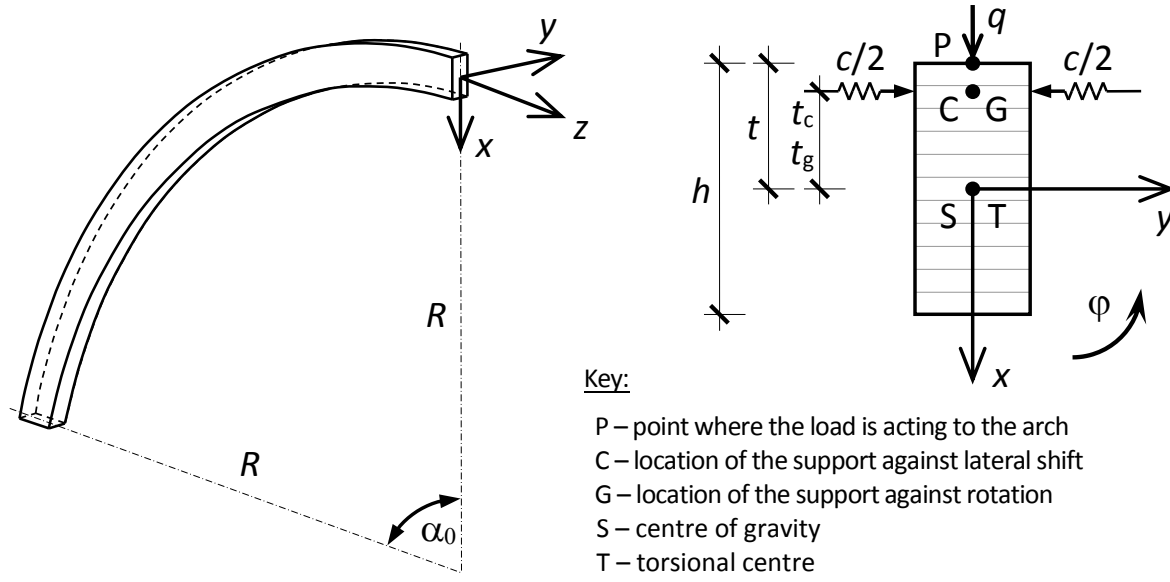

Key:

$\mathrm{P}$ - point where the load is acting to the arch

$\mathrm{C}$ - location of the support against lateral shift

$\mathrm{G}$ - location of the support against rotation

$\mathrm{S}$ - centre of gravity

$\mathrm{T}$ - torsional centre

For the solution of the above differential equation system, the following assumptions and approximations were made:

- The axis of the arch is circular, it has prismatic cross-section (Más, Torres \& Reales, 2017) and the behaviour of the timber material is linear elastic.

- The cross-section of the arch is symmetrical to the plane of the arch.

- The arch is loaded by a radial, uniformly distributed, conservative load, so there is only axial compression acting in it. The external load is acting in the plane of symmetry.

- The curvature of the arch is not too large, that is, the vertical dimensions of the cross section are negligible compared to the arc radius: $1 \pm h / R \approx 1$.

- During lateral torsional buckling of the arch, the fibres parallel to the longitudinal axis elongate to the plane of symmetry in accordance with the asymmetry rule. Thus, due to the transverse bending caused by the lateral movement of the arch, only the fibres in the plane of symmetry remain strain-free.

- During lateral deflection, the cross-sections of the arch retain their original shape, apart from warping perpendicular to their plane. The change in cross-sectional properties due to this bending is neglected.

With the help of equation system (1) and the boundary conditions corresponding to the chosen support, the critical force of the $\operatorname{arch}\left(N=N_{\mathrm{cr}}\right)$ can always be calculated using the known methods of stability theory (Timoshenko \& Gere, 1961). Assuming fork-like support (rotation around the longitudinal axis of the arch is restrained, but rotation around the horizontal axis of the cross section is allowed) at both ends of the arch, the following boundary condition equations apply:

$$
v_{\mathrm{T}}=0 ; \quad \frac{\varphi}{R}-v_{\mathrm{T}}^{\prime \prime}=0 ; \quad \varphi=0 ; \quad \varphi^{\prime \prime}-\frac{1}{R} v_{\mathrm{T}}^{\prime \prime}=0
$$

The unknown displacement functions are taken as:

$$
\begin{aligned}
& \varphi=\sum_{k=1,2,3, \ldots} \varphi_{\mathrm{k}} \sin \left(\lambda_{\mathrm{k}} s\right) \\
& v_{\mathrm{T}}=\sum_{k=1,2,3, \ldots} v_{\mathrm{k}} \sin \left(\lambda_{\mathrm{k}} s\right)
\end{aligned}
$$

where $k=1,2,3, \ldots$ is the number of the half-waves during buckling, $\lambda_{\mathrm{k}}=k \cdot \pi / L, L$ is the length of the centre line of the arch, $s$ is the distance from end of the arch, $\varphi_{\mathrm{k}}$ and $v_{\mathrm{k}}$ are constants. Displacement functions (2) satisfy the boundary conditions referring to fork supports, and the differential equation system (1) too. Substituting the corresponding derivatives of the displacement functions with respect to $s$ into equation system (1), the following expression can be formed: 
$\mathbf{A} \cdot \mathbf{u}=\left[\begin{array}{ll}a_{11} & a_{12} \\ a_{21} & a_{22}\end{array}\right] \cdot\left[\begin{array}{c}v_{\mathrm{k}} \\ \varphi_{\mathrm{k}}\end{array}\right]=\left[\begin{array}{l}0\rceil \\ 0\end{array}\right]$.

The coefficient matrix $\mathbf{A}$ in the previous equation is symmetrical, thus $a_{12}=a_{21}$. The elements of matrix $\mathbf{A}$ are as follows:

$$
\begin{aligned}
& a_{11}=-\lambda_{\mathrm{k}}^{2}\left[G I_{\mathrm{t}}+\lambda_{\mathrm{k}}^{2} E I_{\omega}-N\left(x_{0}^{2}+i_{\mathrm{x}}^{2}+i_{\mathrm{y}}^{2}\right)+g t_{\mathrm{g}}^{2}\right]+\frac{1}{R}\left\lceil N\left(t-x_{0}-\frac{i_{\mathrm{x}}^{2}}{R}\right)-\frac{E I_{\mathrm{x}}}{R}\right\rfloor-c t_{\mathrm{c}}^{2} \\
& a_{12}=a_{21}=-\lambda_{\mathrm{k}}^{2}\left\lceil N x_{0}+\left(G I_{\mathrm{t}}+\lambda_{\mathrm{k}}^{2} E I_{\omega}+E I_{\mathrm{x}}\right) \frac{1}{R}-g t_{\mathrm{g}}\right\rceil+c t_{\mathrm{c}} \\
& a_{22}=\lambda_{\mathrm{k}}^{2}\left[N-\left(G I_{\mathrm{t}}+\lambda_{\mathrm{k}}^{2} E I_{\omega}\right) \frac{1}{R^{2}}-\lambda_{\mathrm{k}}^{2} E I_{\mathrm{x}}-g\right]+c
\end{aligned}
$$

The homogeneous system of equations for $v_{T}$ and $\varphi$ exists only if the determinant of the coefficient matrix is zero, therefore the critical value of the compressive force $\left(N=N_{\mathrm{cr}}\right)$ can be calculated from the condition below:

$$
\operatorname{det}(\mathbf{A})=a_{11} \cdot a_{22}-a_{21}^{2}=0
$$

Substituting the appropriate $a_{11}, a_{12}$ and $a_{22}$ coefficients into (3) a second order equation for $N_{\text {cr }}$ can be obtained:

$$
K_{2} N_{\mathrm{cr}}^{2}+K_{1} N_{\mathrm{cr}}+K_{0}=0 \text { if } \lambda_{\mathrm{k}} \neq 0
$$

Performing the multiplications, and simplifying with $\lambda_{\mathrm{k}}^{2}$ the values of $K_{2}, K_{1}$ and $K_{0}$ coefficients are the following:

$$
\begin{aligned}
K_{2}= & \left(i_{\mathrm{x}}^{2}+i_{\mathrm{y}}^{2}\right) \cdot \lambda_{\mathrm{k}}^{2}+\frac{t-x_{0}}{R}-\frac{i_{\mathrm{x}}^{2}}{R^{2}} \\
K_{1}= & -E I_{\mathrm{x}}\left[\frac{1}{R^{2}}+\lambda_{\mathrm{k}}^{4}\left(x_{0}^{2}+i_{\mathrm{x}}^{2}+i_{\mathrm{y}}^{2}\right)+\lambda_{\mathrm{k}}^{2}\left(\frac{t+x_{0}}{R}-\frac{i_{\mathrm{x}}^{2}}{R^{2}}\right)\right\rfloor-\left(G I_{\mathrm{t}}+\lambda_{\mathrm{k}}^{2} E I_{\omega}\right)\left\lceil\lambda_{\mathrm{k}}^{2}+\frac{1}{R^{2}}\left(\frac{t-x_{0}}{R}-\frac{i_{\mathrm{x}}^{2}}{R^{2}}\right)+\frac{\lambda_{\mathrm{k}}^{2}}{R^{2}} i_{\mathrm{x}}^{2}\right]- \\
& \left.\left.-c \mid\left(x_{0}-t_{\mathrm{c}}\right)^{2}+i_{\mathrm{x}}^{2}+i_{\mathrm{y}}^{2}+\frac{1}{\lambda_{\mathrm{k}}^{2}}\left(\frac{t-x_{0}}{R}-\frac{i_{\mathrm{x}}^{2}}{R^{2}}\right)\right\rfloor-g \mid \lambda_{\mathrm{k}}^{2}\left(x_{0}-t_{\mathrm{g}}\right)^{2}+\lambda_{\mathrm{k}}^{2}\left(i_{\mathrm{x}}^{2}+i_{\mathrm{y}}^{2}\right)+\frac{t-x_{0}}{R}-\frac{i_{\mathrm{x}}^{2}}{R^{2}}\right] \\
K_{0}= & \left.\left.E I_{\mathrm{x}}\left(G I_{\mathrm{t}}+\lambda_{\mathrm{k}}^{2} E I_{\omega}\right)\left(\lambda_{\mathrm{k}}^{2}-\frac{1}{R^{2}}\right)^{2}+c \mid E I_{\mathrm{x}}\left(\lambda_{\mathrm{k}} t_{\mathrm{c}}+\frac{1}{\lambda_{\mathrm{k}} R}\right)^{2}+G I_{\mathrm{t}}+\lambda_{\mathrm{k}}^{2} E I_{\omega}\right]+\right] \\
& \left.+g\left|E I_{\mathrm{x}}\left(\lambda_{\mathrm{k}}^{2} t_{\mathrm{g}}+\frac{1}{R}\right)^{2}+\lambda_{\mathrm{k}}^{2}\left(G I_{\mathrm{t}}+\lambda_{\mathrm{k}}^{2} E I_{\omega}\right)\right|+c g\left(t_{\mathrm{g}}-t_{\mathrm{c}}\right)^{2}\right]
\end{aligned}
$$

Substituting the above $K$ coefficients into equation (4) a closed formula is obtained for the $N_{\text {cr }}$ critical compressive force of a laterally braced, circular arch with fork supports. For the determination of the critical force using the above method, the compressive $(c)$ and shear $(g)$ stiffness of the lateral support for unit arc length must also be known. They can be generally calculated from the geometrical and material properties of the applied bracing system. However, the exact solution of equation system (1) usually involves a number of mathematical difficulties in case of structural configurations typically used in practice. If we want to consider the elastic supportive effect of discrete structural elements - like stiffening trusses - connected to the arch, the structural model and its analytical solution will become much more complicated. In case of such structural configurations, either a numerical analysis, or a more simple approach is may be used to take the supporting effect of bracing truss into account. In the followings such an approximate method using the addition formulas of elastic stability theory (Timoshenko \& Gere, 1961; Kollár, 1999) and considering an equivalent continuous lateral support for the lateral torsional buckling analysis of truss-braced timber arch girders. 


\section{Approximate buckling analysis and consideration of the effect of truss-bracing}

It was assumed, that the lengths of the connected timber arches do not change during the lateral torsional buckling and the applied truss-bracing could be replaced by a spring system distributed along the total length of the arches, limiting lateral deformations. This way the analysis could be simplified to the examination of a single arch with elastic lateral support. The critical force of an elastically bedded arch can be approximately calculated in the following form (Kollár, 1999):

$N_{\mathrm{cr}} \approx N_{\mathrm{cr}, 0}+c \frac{\left(2 \alpha_{0} R\right)^{2}}{\pi^{2} k^{2}}+g$

where $N_{c r, 0}$ is the critical force of the standalone arch without elastic lateral support, $\alpha_{0}$ is the centre angle of the arch length (Figure 2), $k$ is the buckling mode shape (number of half sinusoidal waves forming the buckling shape of the $\operatorname{arch}$ ), $c\left[\mathrm{kN} / \mathrm{m}^{2}\right]$ is the elastic spring coefficient of the bedding against lateral displacement and $g[\mathrm{kN}]$ is the spring coefficient of the bedding against lateral angular distortion. In case of truss-braced arches the value of $g$ can be determined from the geometrical and material characteristics of the truss-bracing. The value of $c$ is approximately zero for truss-braced arches, where the buckling shape of the arch typically consists of two or more half sinusoidal waves, that is the buckling mode shape is $k \geq 2$ (Kollár, 1982).

\section{Determination of the equivalent shear stiffness of the lateral truss-bracing}

For the determination of the $g$ spring coefficient of the effective bedding against lateral angular distortion, the deformation of the supporting truss was analysed in case of different truss-brace types (Figure 3). First the $v$ lateral deformation of a truss-unit of length $b$ of the connected arch pair due to the bar forces produced by an $M$ bending moment was determined (Figure 4). For instance, in case of type II bracing the lateral deformation was calculated as follows:

$$
v=2 \cdot \frac{M}{b \cdot \sin \alpha} \cdot \frac{1}{\sin \alpha} \cdot \frac{d}{E \cdot A_{\mathrm{r}}}+V \cdot 2 \cdot \frac{a}{E \cdot A_{\mathrm{o}}}
$$

where $d$ is the length of the diagonal bars, $a$ is the distance of the connected arches, $\alpha$ is the inclination of the diagonals, $E$ is the elastic modulus of the corresponding timber material, $A_{r}$ and $A_{\circ}$ are the cross-sectional areas of the diagonals and transverse bars, respectively, and $V=M / b$ is the shear force from the $M$ bending moment.
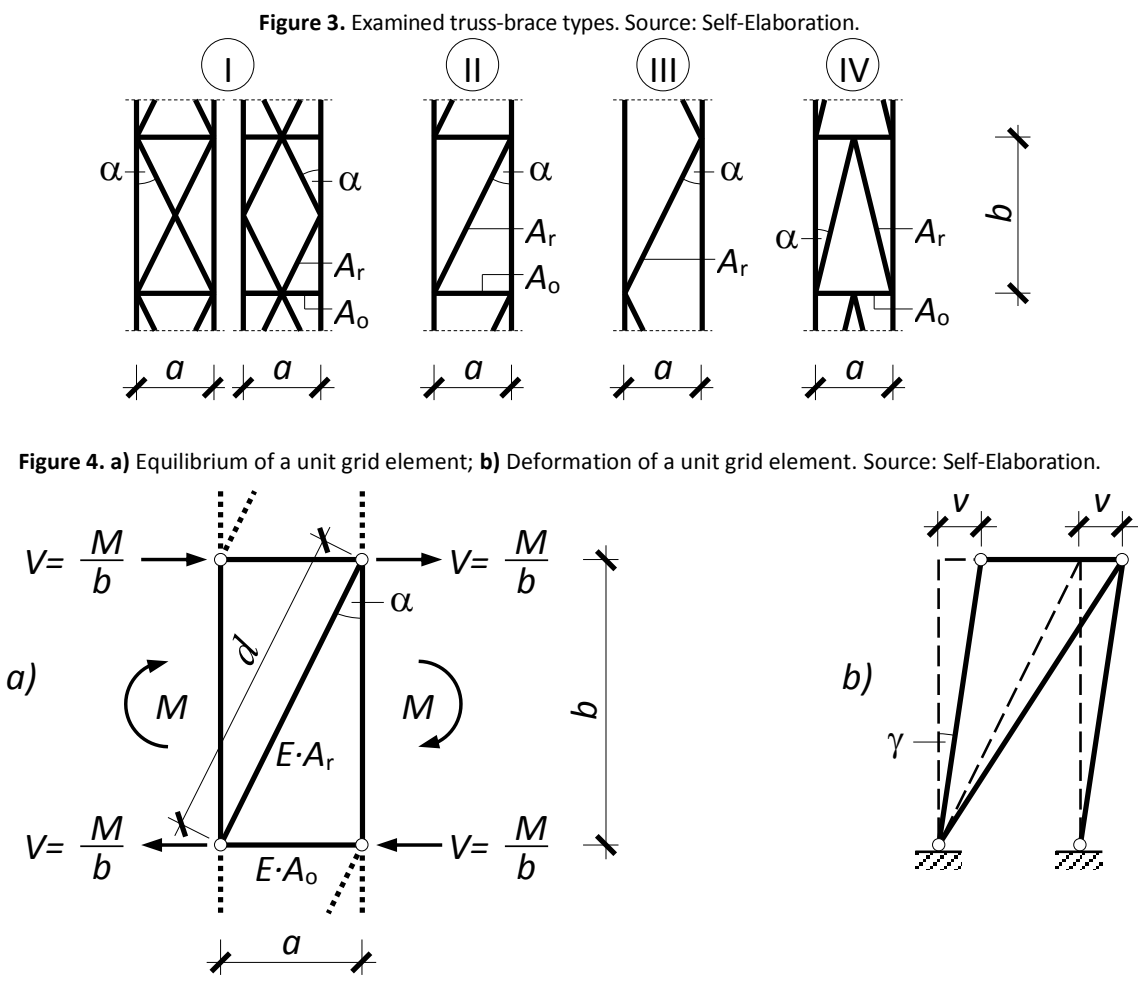
Using the theory of small deformations the angular distortion of a unit grid element (Figure 4.b) was expressed as the ratio of the $v$ lateral deformation and the $b$ length of a truss-unit. In case of type II bracing system the angular distortion was expressed in the following form:

$$
\gamma=\frac{v}{b}=V\left(\frac{2 \cdot d}{b \cdot \sin ^{2} \alpha \cdot E \cdot A_{\mathrm{r}}}+\frac{2 \cdot a}{b \cdot E \cdot A_{\mathrm{o}}}\right)
$$

Taking the value of angular distortion as unit $(\gamma=1)$, the equivalent specific elastic spring coefficient of truss-bracing can be calculated as the ratio of the $M$ bending moment and the $b$ length of a truss-unit. In case of type II trussbracing the equivalent $g$ spring coefficient concerning the connected pair of arches was determined from:

$$
g=V=\frac{M}{b}=\frac{1}{2} \frac{1}{E \cdot A_{\mathrm{r}} \cdot \sin ^{2} \alpha \cdot \cos \alpha}+\frac{1}{E \cdot A_{\mathrm{o}} \cdot \cot \alpha}
$$

Most typical structural configurations of truss types (I, II, III and IV) used for the bracing of timber arch pairs are illustrated in Figure 3. The equivalent spring coefficients for different truss types can be determined the same manner as described above. Introducing the $\beta=A_{0} / A_{r}$ parameter the spring coefficient for a pair of arches in case of different truss-brace types can be calculated as:

$$
\begin{aligned}
& g_{\mathrm{I}}=E \cdot A_{\mathrm{r}} \frac{\sin ^{2} \alpha \cdot \cos \alpha \cdot \cot \alpha \cdot \beta}{2 \cdot \cos \alpha \cdot \sin ^{2} \alpha+\beta \cdot \cot \alpha} \\
& g_{\mathrm{II}}=E \cdot A_{\mathrm{r}} \frac{\sin ^{2} \alpha \cdot \cos \alpha \cdot \cot \alpha \cdot \beta}{2\left(\cos \alpha \cdot \sin ^{2} \alpha+\beta \cdot \cot \alpha\right)} \\
& g_{\mathrm{III}}=\frac{1}{2} E \cdot A_{\mathrm{r}} \cdot \sin ^{2} \alpha \cdot \cos \alpha \\
& g_{\mathrm{IV}}=E \cdot A_{\mathrm{r}} \frac{\sin ^{2} \alpha \cdot \cos \alpha \cdot \cot \alpha \cdot \beta}{\cos \alpha \cdot \sin ^{2} \alpha+\beta \cdot \cot \alpha}
\end{aligned}
$$

Based on the previous equations, the $g$ equivalent spring coefficient depends on the geometry and elastic modulus of the bracing truss only. If the $g$ spring coefficient concerning the pair of arches and the $N_{c r, 0}$ critical force of the original arch without lateral support are known, the critical force of the truss-braced arch $\left(N_{\mathrm{cr}}\right)$ may be calculated from the analytical equation (4) or from the approximate formula (5). This approximation can be also used in case of load configurations and support conditions different than the presented one.

\section{Application of the introduced calculation method}

\section{Data of the analysed timber arch}

The side view and cross-section of the analyzed double-hinged, circle shaped timber arch is shown in Figure 5.a. The arch is loaded by the $p$ uniformly distributed radial load, which causes only axial compression in the arch cross-section. Two supports restrict horizontal displacements and allow the arch only to rotate around the global out-of-plane axis. The arch is laterally braced with type II timber truss (Figure 5.b).

The main geometrical data and material properties of the structure are as follows: radius of the arch is $R=9.30 \mathrm{~m}$, span of the $\operatorname{arch}$ is $l=18 \mathrm{~m}$, the centre angle of the arch length is $\alpha_{0}=75.41^{\circ}$, lateral distance of the connected arches is $a=2.00 \mathrm{~m}$, cross-sectional size of the arch is $600 \times 160 \mathrm{~mm}$, cross-sectional area of diagonal bars is $A_{\mathrm{r}}=50 \times 120=6000 \mathrm{~mm}^{2}$, cross-sectional area of the transverse bars is $A_{0}=50 \times 100=5000 \mathrm{~mm}^{2}$, the value of $\beta$ parameter is $\beta=A_{0} / A_{r}=0.833$, the inclination of the diagonals is $\alpha=39.25^{\circ}$ and the elastic modulus of the timber material parallel to grain is $E=10^{7} \mathrm{kN} / \mathrm{m}^{2}$. 


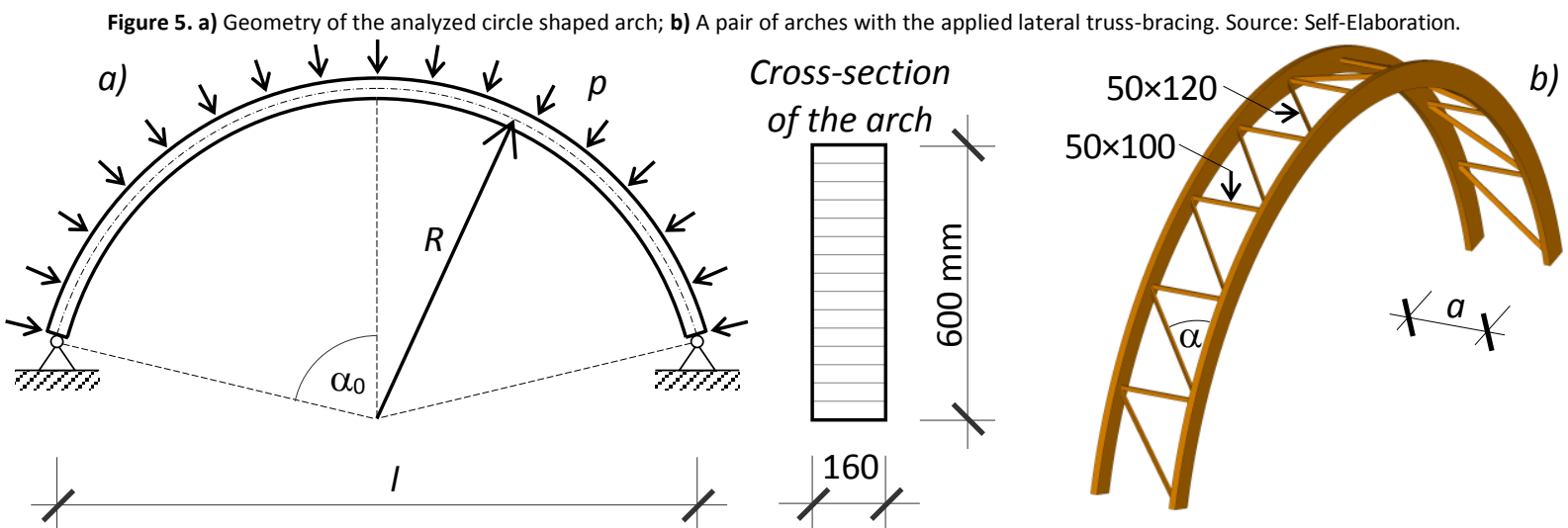

Results of analytical and numerical analyses

The critical force of the arch in question was calculated by the analytical method and by the approximate method described before and for the sake of comparison, the critical force was also determined by numerical method. Numerical analysis was performed with AxisVM $13^{\circledR}$ finite-element software, taking line elements, linear elastic material behaviour and geometric nonlinearity into account. The degree of freedom (DOF) per node was 6 and the length of the applied finite elements was about $I / 120=0.15 \mathrm{~m}$. Geometric nonlinearity means that the equilibrium was established with respect to the deformed line elements. Depending on the magnitude of displacement second or third order analysis was performed. The loads were conservative; they kept their initial direction during the deformation. AxisVM software determines the lowest buckling load multipliers and the corresponding mode shapes, and it also verifies whether the required number of the lowest eigenvalues has been determined. The buckling load multiplier $n_{c r}=\lambda_{c r}$ is computed, solving the eigenvalue problem, where $\lambda_{c r}$ is the smallest eigenvalue and the corresponding eigenvector is the buckling mode shape. In our case is the $N_{\text {cr }}$ critical force for different mode shapes was derived as the product of the $N$ axial force in the arch cross-section from the given $p$ load and the corresponding $n_{\mathrm{cr}}$ load multiplier. The maximum number of iterations needed for stability analysis was about 30 . The Eigen value convergence criterion was set to $10^{-10}$ and the Eigenvector convergence criterion was $10^{-5}$.

First the critical force of the arch without lateral support $(g=0)$ was determined using the above three methods. The first ten buckling mode shapes (Figure 6) were examined by the introduced analytical and numerical methods, while the approximate method provided the value of critical force for the critical mode shape only. Figure 7 shows the critical forces calculated by the analytical and numerical methods in case of different buckling mode shapes. The values of critical force causing the lateral torsional buckling of the un-braced arch, calculated by different methods are presented in Table 1. It can be seen that the critical force of the arch is rather small without lateral support, because the $2 \alpha_{0}=150.82^{\circ}$ the centre angle of the arch length is relatively close to $180^{\circ}$, in which case the critical force is $N_{\mathrm{cr}}=0 \mathrm{kN}$ (in case of the applied fork support and $180^{\circ}$ centre angle the arch "lies down" like a rigid body without any resistance).

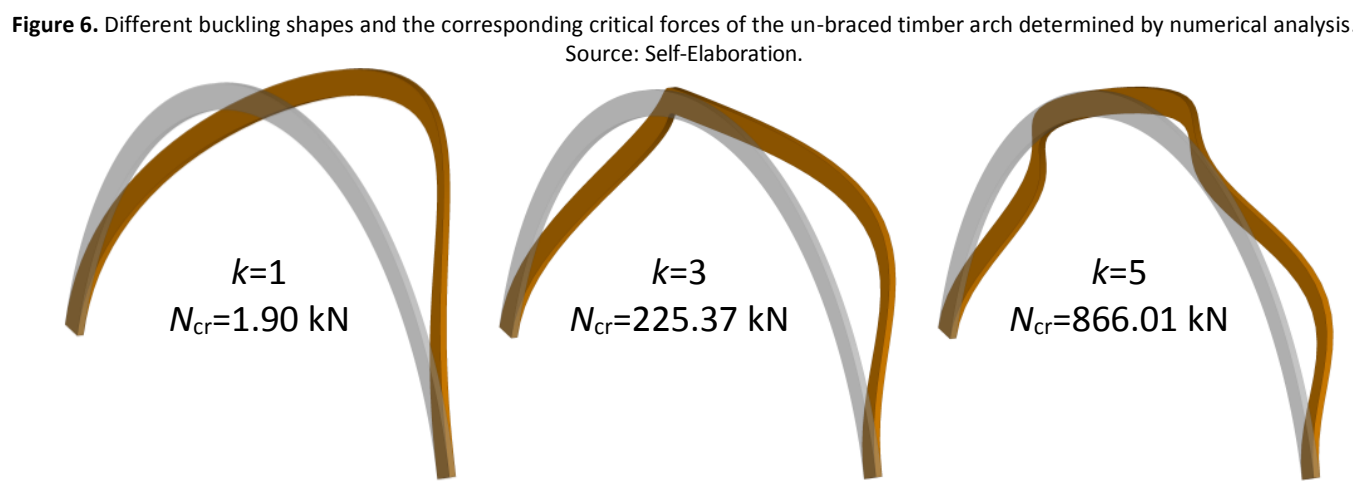

In the second step, the analysis of a standalone arch with continuous lateral support was carried out. The $g$ equivalent shear stiffness provided by the applied type II truss-bracing was determined from (6) and it was taken into account for both analytical and the numerical calculations. Figure 7 shows the critical forces obtained by the analytical and numerical methods in case of different buckling mode shapes and $g=3566.05 \mathrm{kN}$ equivalent lateral shear stiffness. The values of critical force causing the lateral torsional buckling of the continuously supported arch, calculated by different methods are presented in Table 1. 


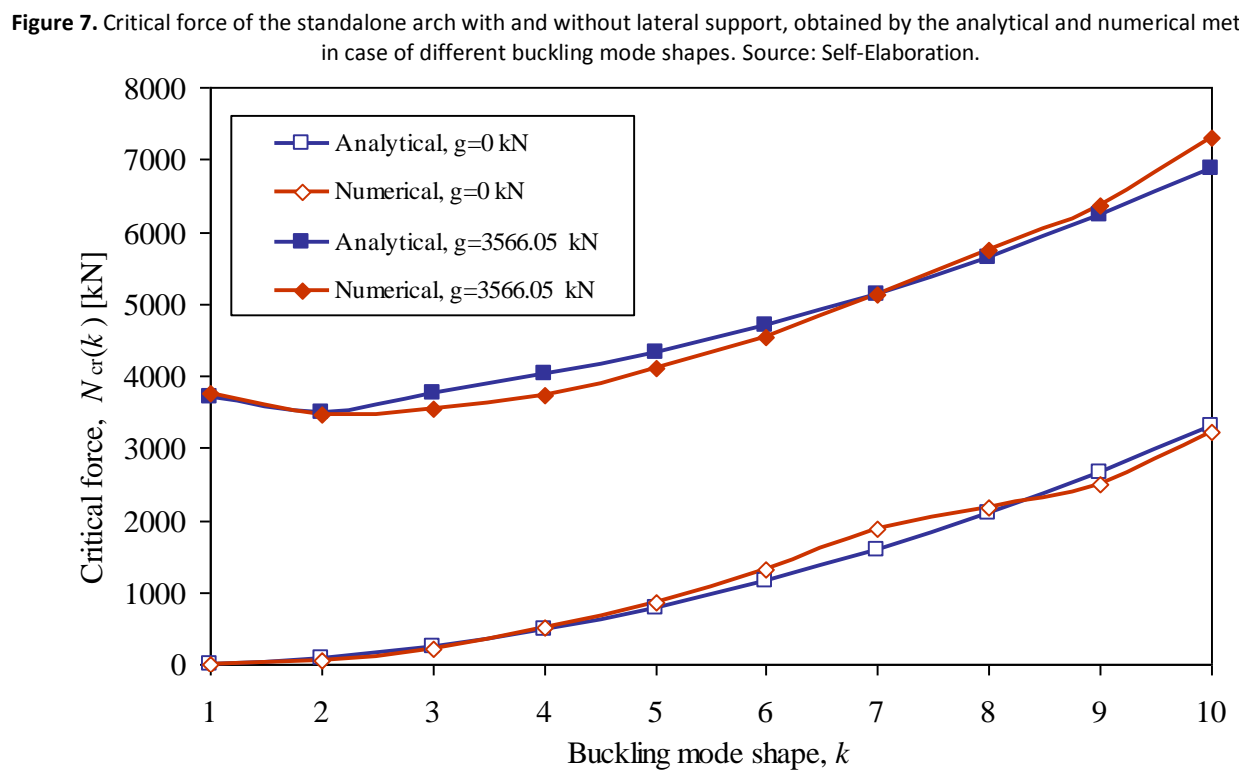

In case of the introduced analytical and approximate methods the effect of truss-bracing is taken into account by an equivalent continuous lateral support only. However, the applied numerical method can also be used to determine the critical force of an arch pair that is actually stiffened by a bracing-truss. Therefore, the numerical analysis of the truss-braced arch pair (Figure 8.a) was also completed. It is typical in practice that more than two timber arches are connected longitudinally (e.g. by purlins) which increases the lateral torsional buckling resistance of the examined arch. For this reason, an additional case was also numerically analysed, where the truss-braced arch pair is laterally connected to a third arch by the applied transverse bars (Figure 8.b). For practical reasons, in both cases the supporting arches were loaded with self-weight only. Taking self-weight into account for supporting arches instead of radial load having the same intensity resulted in a difference of about $0.7 \%$ in the critical force according to our calculations. The values of critical force causing the lateral torsional buckling of the truss-braced arch, calculated by different methods are also presented in Table 1.

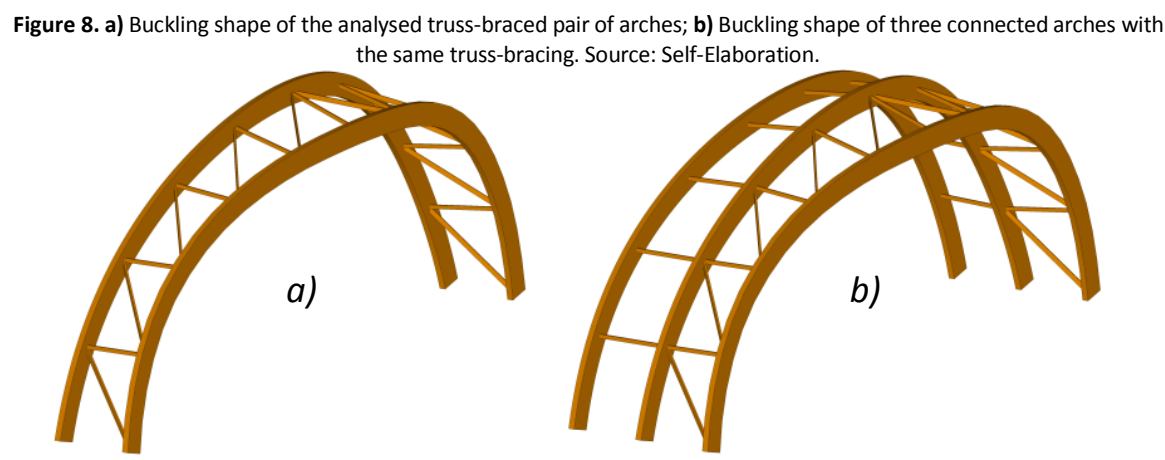

Table 1. Values of critical force calculated by different methods. Source: Self-Elaboration.

\begin{tabular}{lccc}
\multicolumn{3}{c}{ Table 1. Values of critical force calculated by different methods. Source: Self-Elaboration. } \\
\cline { 2 - 4 } & \multicolumn{3}{c}{ Critical force, $N_{\mathrm{cr}}[\mathrm{kN}]$} \\
\cline { 2 - 4 } Analysed structural configuration & $\begin{array}{c}\text { Analytical } \\
\text { method }\end{array}$ & $\begin{array}{c}\text { Numerical } \\
\text { Method }\end{array}$ & $\begin{array}{c}\text { Approximate } \\
\text { method }\end{array}$ \\
\hline $\begin{array}{l}\text { Standalone arch without lateral support }(g=0) \\
\text { Standalone arch with continuous lateral support }\end{array}$ & 1.84 & 1.90 & 1.84 \\
( $g=3566.05 \mathrm{kN})$ & 3500.33 & 3468.42 & 3567.89 \\
$\begin{array}{l}\text { A pair of arches with type II lateral truss-bracing } \\
\text { ( } g=3566.05 \mathrm{kN})\end{array}$ & 3500.33 & 3418.02 & 3567.89 \\
$\begin{array}{l}\text { Three connected arches with type II lateral } \\
\text { truss-bracing }(g=3566.05 \mathrm{kN})\end{array}$ & 3500.33 & 3478.04 & 3567.89 \\
\hline
\end{tabular}


According to the results in Table 1 the effect of truss-bracing is significant in case of two or more connected arches. In case of the analysed structure the increase of critical force due the application of truss-bracing was up to two orders of magnitude greater than the critical force of the un-braced arch. It means that the application of appropriate lateral bracing may lead to more economical structural configuration for timber arch structures. Of course, during the design the calculated value of critical force may be limited by the strength failure of the arch cross-section or by the buckling truss members. Comparing the critical forces obtained by the different methods, it can be stated that the differences are rather small. In case of the un-braced arch the analytical and approximate methods yield to the same solution and the value of the numerically calculated critical force is only $3.2 \%$ higher. In case of the standalone arch with continuous lateral support, the numerically and approximately calculated values of the critical force differ from the analytical solution by $0.9 \%$ and $1.9 \%$, respectively. The numerically calculated critical force of the truss-braced pair of arches differs by $2.4 \%$ from the analytical solution and $4.4 \%$ from the approximate solution. These differences are even smaller if more than two supporting arches are considered. Based on these results the proposed approximate method also satisfies the accuracy requirements of the engineering practice in case of the analysed timber arch structure. In addition to its simplicity, another advantage of the presented approximate method is that the critical force of the un-braced arch $\left(N_{\mathrm{cr}, 0}\right)$ contains the characteristics of the given timber arch only, while the $g$ spring coefficient representing the truss-bracing depends only on the geometrical and material properties of the bracing truss. It means that the approximate method can be used for preliminary design in many cases where the critical force causing the elastic lateral torsional buckling of the un-braced arch is known from the literature.

\section{Results of the parametric analysis of different truss-brace configurations}

Buckling of the timber arch in question was analysed in case of different truss-braced configurations using the analytical approach. The effect of the truss-bracing type (I-IV) and the ratio of diagonal and transverse bar crosssections $(\beta)$ on the increase of critical force $\left(n=N_{\mathrm{cr}} / N_{\mathrm{cr}, 0}\right)$ is presented in Figure 9 . The inclination of the diagonals, relative to the plane of the arch was $\alpha=45^{\circ}$ in each case.

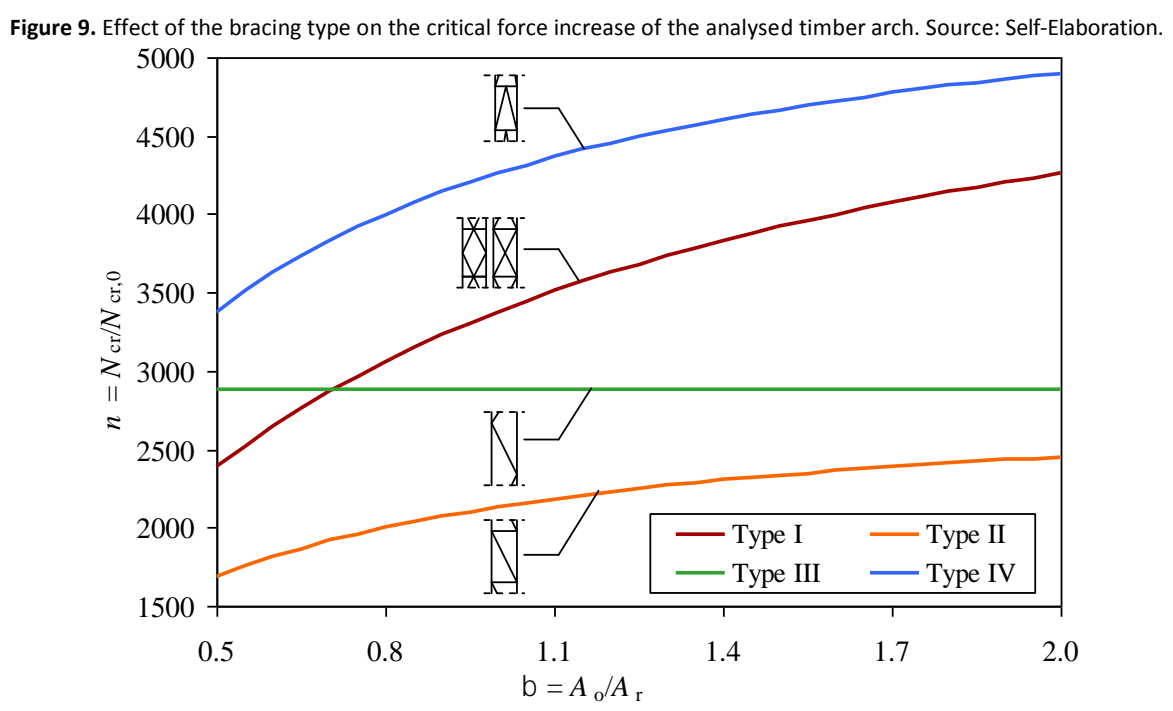

According to Figure 9 type IV truss-bracing is the most effective, and type II is the least effective in increasing the critical force of the arch. It can also be observed, that the increase of critical force is higher if the cross-section of transverse bars is bigger than the cross-section of the diagonals. During the design of timber arch structures, the type of applied truss-bracing also depends on the axial strength of the arch. In fact, higher critical force can be achieved using type IV truss-bracing for the examined structure, but then the strength failure of the arch cross-section due to compression parallel to grain precedes the lateral torsional buckling phenomenon. This means that the application of type II bracing is sufficient for the given structure. Cross-sectional dimensions and material properties of the truss members must be of course selected by keeping the ratio $\beta$ so that the strength and stability requirements of diagonals and transverse bars are fulfilled. In case of inappropriate buckling resistance of the diagonals or transverse bars, their cross-sections must be increased to make them satisfactory. In this case the value of calculated critical forces will be higher than the values shown in Figures 9-10. However, increasing the cross-sections of the diagonals and transverse bars in the same proportion will not alter the conclusions of the presented parametric analysis.

The effect of diagonals' inclination $(\alpha)$ and the ratio of diagonal and transverse bar cross-sections $(\beta)$ on the increase of critical force causing the lateral torsional buckling of the examined arch is presented in Figure 10. According to the figure 
both $\alpha$ and $\beta$ factors have a strong influence on the increase of the critical force $(n)$. As already stated above, the increase of critical force is higher in case of stronger transverse bars compared to diagonals. While also depending on the value of the $\beta$ factor, the proper inclination of the diagonals can help to maximize the increase of the critical force. Figure 10.a shows that for the examined arch, $\alpha=40 \div 50^{\circ}$ diagonal inclinations are more effective, while very steep or very flat inclinations are not so effective in this area. Related to this, the critical force as a function of the $\alpha$ inclination is presented in Figure 10.b. Plotting the curves corresponding to different $\beta$ ratios, the optimal value of the inclination ( $\alpha_{\text {opt }}$ ) can be determined for the given structural configuration. For the examined structure the value of $\beta$ factor is 0.833 and thus based on the corresponding curve of Figure 10.b the optimal value of the inclination is $\alpha_{\mathrm{opt}}=45.76^{\circ}$ which is slightly higher than the currently applied angle.

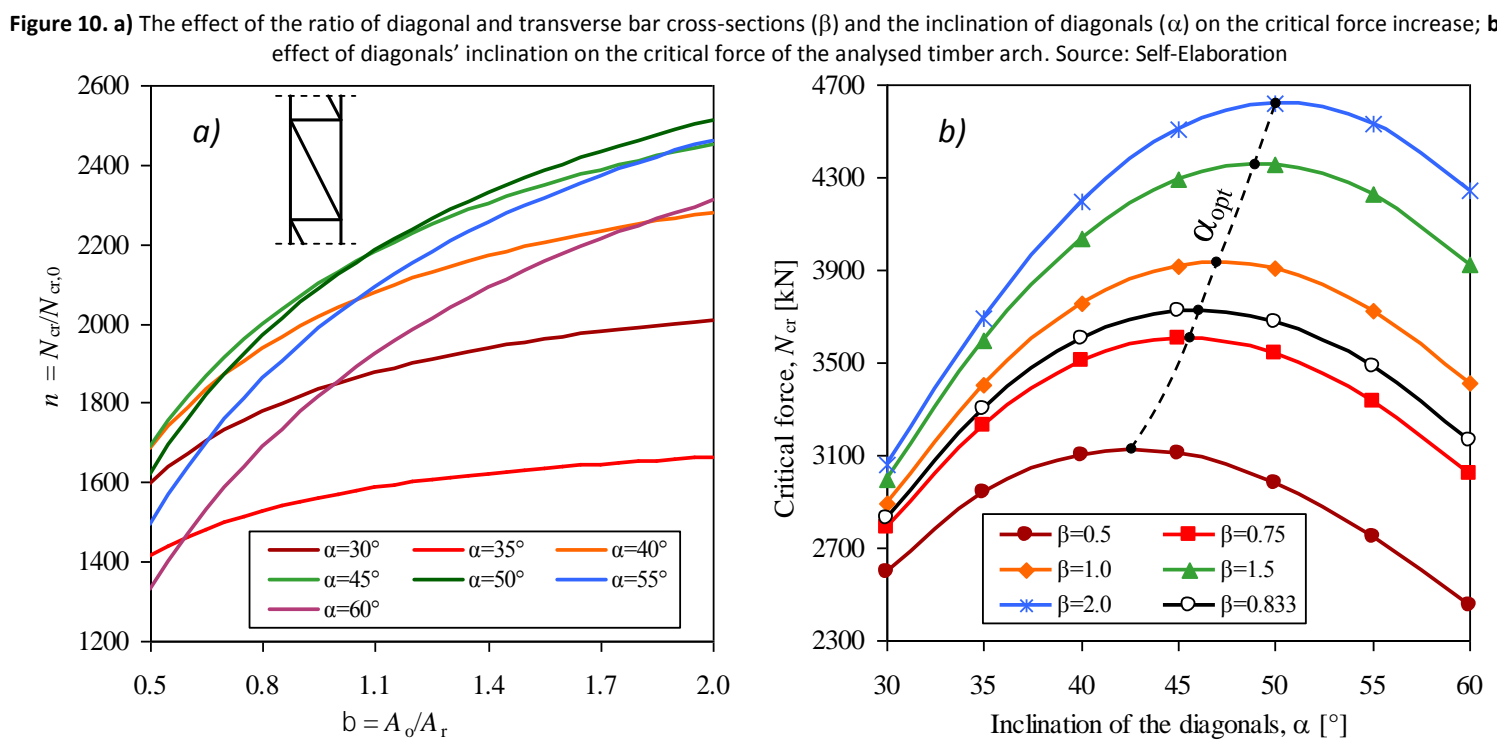

An analytical solution, as well as an approximate method was presented for the calculation of critical force causing the lateral torsional buckling of truss-braced timber arch structures. According to the analysis of a circular timber arch braced with different truss types, the effect of lateral bracing was significant in each case. In most of the examined cases the critical force causing the lateral torsional buckling of the truss-braced structure was up to two orders of magnitude greater than the critical force without bracing. The analytical and approximate solutions on the critical force were compared to the results of numerical analyses. The maximum difference of the results obtained by different methods was less than $5 \%$ for the examined structure, meaning that also the proposed approximate method satisfies the accuracy requirements of the engineering practice. The application of lateral truss bracing is usually necessary for the compliance of a timber arch structure, and it may also lead to more economical structural configuration in terms of lateral torsional buckling. Both analytical and approximate method presented in the article can be used to determine the optimal inclination of the diagonals, and to select the appropriate ratio of diagonal and transverse bar cross-sections in order to maximize the critical force of the laterally braced arch. The proposed approximate method can be easily applied for preliminary design of timber arches, in case of load configurations and support conditions different than the presented one too. A further advantage of both analytical and approximate solutions is that the critical force of the un-braced arch contains the characteristics of the given timber arch only, while the spring coefficient representing the lateral supportive effect of truss-bracing depends only on the geometrical and material properties of the bracing truss, keeping the assumed simplifications in mind. Thus the introduced methods can be used in many cases where the critical force causing the lateral torsional buckling of the unbraced timber arch is already known from the literature or from another (e.g. numerical) analysis.

References

Balaž, I. (2005). Lateral torsional buckling of timber beams, Wood Research, 50(1), 51-58.

Bell, K., \& Eggen, T. E. (2004). Stability of timber beams and columns. Proceedings of the $8^{\text {th }}$ World Conference on Timber Engineering, WCTE 2004, Lahti, Finland, pp. 1-7. 
Crocetti, R. (2016). Large-span timber structures. Proceedings of the World Congress on Civil, Structural, and Environmental Engineering, CSEE'16, Prague, Czech Republic, pp. 1-23.

Eggen, T. E. (2000). Buckling and geometrical nonlinear beam-type analyses of timber structures (Doctoral dissertation). Retrieved from //ntnuopen.ntnu.no/ntnu-xmlui/bitstream/handle/11250/2480139/Dr_avhandling_TE_Eggen.pdf

EN 1995-1-1 (2015). Eurocode 5: Design of timber structures - Part 1-1: General - Common rules and rules for buildings. Brussels, European Committee for Standardization.

Guo, Y-L., Zhao, S-Y., Dou, C., \& Pi, Y-L. (2014). Out-of-plane elastic buckling of circular arches with elastic end restraints. Journal of Structural Engineering, 140(10), 1-9.

Kollár, L. (1982). Supporting effect of the fabric of tent structures stretched onto an arch row on the lateral stability of the arches. Acta Technica, 94(3-4), 197-214.

Kollár, L. (1999). Structural stability in engineering practice. London, E \& FN Spon.

Kollár, L., \& Bódi, I. (1984). Lateral stability of arches with elastic support against lateral displacement and rotation (in Hungarian). Épités Építészettudomány, 16(1-2), 63-71.

Kuhlmann, U., \& Teichmann, G. (2006). Influence of creep and moisture on the lateral torsional buckling of timber beams. Proceedings of the $6^{\text {th }}$ PhD Symposium in Civil Engineering, Zürich, pp. 1-8.

Lima, N-H., \& Kang, Y-J. (2004). Out of plane stability of circular arches. International Journal of Mechanical Sciences 46, $1115-1137$.

Más, R. I., Torres, J. C. P. \& Reales, J. R. A. (2017). Prismatic structural members: Cross section flat and normal to the axis? Revista de la Construcción, 16(3), 507-517.

Padmoes, D. A. (1990). Flexural-torsional buckling of timber portal frames. (Doctoral dissertation). Retrieved from //pure.tue.nl/ws/files/3566602/332565.pdf

Pi, Y-L., \& Bradford, M. A. (2004). Elastic flexural-torsional buckling of fixed arches. Quarterly Journal of Mechanics and Applied Mathematics, 57(4), 551-569.

Pi, Y-L., Bradford, M. A., Trahair, N. S., \& Chen, Y-Y. (2005). A further study of flexural-torsional buckling of elastic arches. International Journal of Structural Stability and Dynamics, 5(2), 163-183.

Rodman, U., Saje, M., Planinc, I., \& Zupan, D. (2013). The lateral buckling of timber arches. International Journal of Structural Stability and Dynamics, 13(8), 1-16.

Sherzad, R., \& Imamzada, A. (2015). Buckling and Geometric Nonlinear Stress Analysis - Circular glulam arched structures (Master's thesis). Retrieved from //Inu.diva-portal.org/smash/get/diva2:947180/FULLTEXT01.pdf

Teichmann, G. (2006). Influence of creep and moisture on the lateral torsional buckling of timber beams. Proceedings of the $6^{\text {th }}$ PhD Symposium in Civil Engineering, Zürich, pp. 1-8.

Timoshenko, S. P., \& Gere, J. M. (1961). Theory of Elastic Stability. New York, McGraw-Hill - Technology \& Engineering.

Tokarz, F. J., \& Sandhu, R. S. (1972). Lateral-torsional buckling of parabolic arches. Journal of the Structural Division, 98(ST5), 1161-1179.

Wollebæk, L., \& Bell, K. (2004). Stability of glulam arches. Proceedings of the $8^{\text {th }}$ World Conference on Timber Engineering, WCTE 2004, Lahti, Finland, pp. 1-6.

Xiao, Q. (2014). Lateral torsional buckling of wood beams (Master's thesis). Retrieved from //ruor.uottawa.ca/bitstream/10393/31174/1/Xiao_Qiuwu_2014_thesis.pdf

Yoo, C. H. (1982). Flexural-torsional stability of curved beams. Journal of the Engineering Mechanics Division, 108(6), 1351-1369. 